\title{
PENGENDALIAN SUHU SECARA ELEKTRONIS PADA MESIN SINTERING FURNACE BERBASIS THYRISTOR
}

\author{
Asep Najmurrokhman, Ahmad Daelami, Fisa Rumanto \\ Jurusan Teknik Elektro Universitas Jenderal Achmad Yani \\ Jl. Terusan Jend. Sudirman PO Box 148 Cimahi 40533 \\ Email : asepnajmu@yahoo.com
}

\begin{abstract}
Abstrak
Mesin sintering furnace adalah sebuah tungku listrik dengan daya dan suhu tinggi untuk menghasilkan produk yang terbuat dari logam atau keramik dengan kualitas baik. Faktor kualitas dalam produk tersebut ditunjukkan oleh nilai kekerasan benda kerja yang dihasilkan dan sangat bergantung kepada suhu dalam mesin tersebut. Karena berbagai faktor yang ada dalam sistem dan lingkungan, suhu yang dihasilkan dalam tungku tersebut kadang-kadang mengalami perubahan dari nilai yang seharusnya. Oleh karena itu, pengendalian suhu dalam mesin ini menjadi bagian yang cukup penting agar dihasilkan benda kerja dengan kualitas baik. Dalam makalah ini dipaparkan tentang pengendalian suhu dalam mesin sintering furnace secara elektronis menggunakan peralatan utama yang disebut thyristor. Thyristor adalah sebuah peralatan elektronis berbasis semikonduktor yang dapat mengatur arus dan tegangan tinggi. Pengendalian suhu ini dilakukan dengan mengatur katup gas panas yang dialirkan ke ruang bakar sesuai dengan kondisi suhu sebenarnya yang terdeteksi oleh transduser suhu. Dari hasil pengamatan terhadap pengujian yang dilakukan terlihat bahwa suhu dapat diatur sesuai dengan set point-nya, meskipun terlihat bahwa ada fluktuasi di sekitar nilai tersebut.
\end{abstract}

Kata kunci: furnace, pengendalian suhu, sintering, thyristor.

\section{Pendahuluan}

Sintering adalah teknik pembentukan benda dan bahan dengan kepadatan tertentu dari serbuk logam dan atau keramik oleh suatu energi panas [Kang, 2005]. Proses sintering menyebabkan bersatunya partikelpartikel, sehingga akan menyebabkan kepadatannya bertambah. Selama proses ini akan terbentuk batas-batas butir yang merupakan tahap permulaan rekristalisasi. Sintering adalah metode yang digunakan untuk membuat benda dari butiran atau serbuk [Wikipedia, 2011]. Proses sintering bekerja berdasarkan prinsip difusi atom. Difusi terjadi dalam setiap materi pada suhu di atas nol mutlak, tetapi proses tersebut berlangsng jauh lebih cepat pada suhu yang lebih tinggi. Dalam sebagian besar proses sintering bahan serbuk ditempatkan dalam cetakan dan kemudian dipanaskan sampai suhu di bawah titik lelehnya. Atom dalam partikel serbuk tersebut menyebar melintasi batas-batas partikel, bergabung bersamasama dan membentuk satu bagian padat.

Sintering secara tradisional digunakan untuk pembuatan benda keramik tetapi menemukan aplikasi di hampir semua bidang industri. Studi tentang proses sintering dan serbuk atau butiran logam dikenal sebagai metalurgi serbuk. Beberapa penelitian mengungkapkan bahwa suhu sangat berpengaruh pada kualitas material yang dibuat melalui proses sintering [Herhady \& Sukarsono (2007), Subiyanto \& Subowo (2003)]. Herhady \& Sukarsono (2007) melakukan penelitian tentang efek suhu pada pembuatan bahan yang digunakan pada reaktor nuklir dan 
menyimpulkan tentang suhu optimal agar diperoleh hasil yang baik. Subiyanto \& Subowo (2003) memperoleh kaitan antara suhu pada proses sintering dengan sifat mekanik dan insulator listrik dari bahan keramik. Karena berbagai faktor yang ada dalam sistem dan lingkungan, suhu yang dihasilkan dalam proses sintering tersebut kadang-kadang mengalami perubahan dari nilai yang seharusnya. Oleh karena itu, pengendalian suhu dalam proses tersebut menjadi bagian yang cukup penting agar dihasilkan benda kerja dengan kualitas baik. Salahsatu komponen yang sangat penting dalam pengendalian suhu tersebut adalah sensor dan aktuatornya. Salah satu sensor suhu yang banyak digunakan adalah jenis termokopel. Sutarya (2008) menggunakan sensor ini dan melakukan analisis terhadap kualitas sensor tersebut dalam proses sintering dalam instalasi bahan bakar reaktor nuklir.

Dalam makalah ini dipaparkan tentang pengendalian suhu dalam mesin sintering furnace secara elektronis menggunakan peralatan utama yang disebut thyristor. Thyristor adalah sebuah peralatan elektronis berbasis semikonduktor yang dapat mengatur arus dan tegangan tinggi. Pengendalian suhu ini dilakukan dengan mengatur katup gas panas yang dialirkan ke ruang bakar sesuai dengan kondisi suhu sebenarnya yang terdeteksi oleh transduser suhu.

\section{Mesin Sintering Furnace}

Furnace adalah salah satu peralatan penukar panas dengan pembakaran bahan bakar dalam burner sebagai sumber panas. Dalam era modern, perkembangan teknologi furnace semakin pesat seiring dengan bertambahnya waktu. Penggunaan furnace sebagai alat untuk pemanas tidak lagi menggunakan sistem konvensional. Saat ini telah ditemukan dan dikembangkan penggunaan furnace dengan menggunakan sistem elektris dengan berbagai kelebihan yang dimiliki. Seperti penggunaan suhu yang tinggi dalam waktu singkat, suhu dapat diatur sesuai kebutuhan, kerugian akibat penguapan udara panas sangat kecil, serta pengaturan kestabilan suhu yang lebih baik.

Furnace pada penelitian ini digunakan untuk mengeraskan benda kerja dan mempertahankan dimensi benda kerja sehingga digunakan pola pemanasan tertentu mengikuti fungsi waktu. Furnace memiliki tingkat derajat suhu yang tinggi, dalam pengerasan benda kerja yaitu sekitar $1155^{\circ} \mathrm{C}$. Dengan karakteristik yang demikian, bila furnace digunakan dalam jangka waktu yang lama, maka kestabilan dari suhu tersebut harus selalu dijaga. Idealnya furnace harus memanaskan bahan secukupnya sampai mencapai suhu yang maksimun. Kunci dari operasi furnace yang efisien terletak pada pemanasan bahan bakar yang sempurna dengan udara berlebih yang minim. Gambar 1 memperlihatkan bagian dalam mesin sintering furnace saat belum dipanaskan.

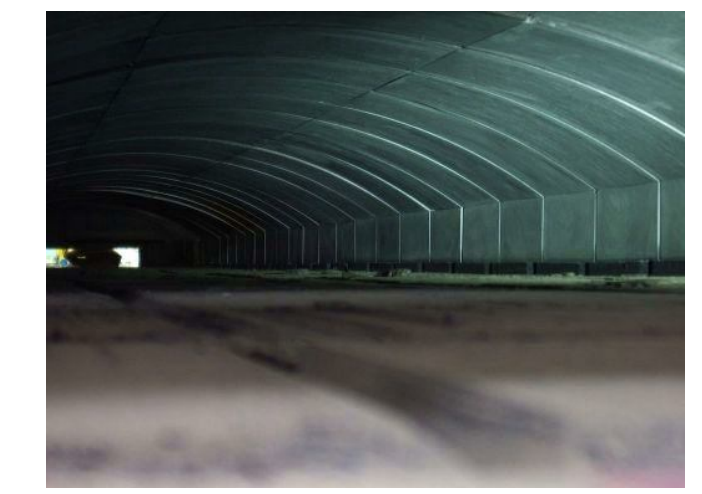

Gambar 1. Bagian Dalam Mesin Sintering Furnace saat belum dipanaskan

\section{Pengendalian Suhu dengan Thyristor}

\subsection{Pengendalian Suhu}

Pengendalian suhu adalah proses yang bertujuan memperoleh suhu yang diinginkan. Meskipun pemanasan dengan heater dalam mesin sintering furnace ditujukan untk memperoleh suhu yang diinginkan, tetapi adanya faktor luar yang berpengaruh menyebabkan suhu tersebut menyimpang dari suhu yang diinginkan. Dalam hal ini dibutuhkan perangkat yang berfungsi untuk mengendalikan suhu 
tersebut, yaitu sebuah kontroler suhu. Sebuah sensor/transduser suhu diperlukan untuk mendeteksi suhu sebenarnya dalam proses tersebut kemudian datanya digunakan untuk mengubah parameter tertentu dalam perangkat kontroler suhu. Ada tiga tipe dasar kontroler, yaitu on/off, proporsional dan PID.

\subsection{Kontroler on/off}

Kontroler on/off adalah bentuk paling sederhana dari kontroler dalam sistem pengendalian suhu. Output dari perangkat ini berada dalam status on atau off. Kontroler on/off akan berpindah output hanya ketika suhu melintasi setpoint. Kondisi on terjadi saat suhu berada di bawah setpoint, sedangkan off berlangsung saat suhu output berada di atas setpoint. Karena suhu melintasi setpoint untuk mengubah keadaan output, suhu proses akan berosilasi terus. Nilai suhu tersebut bergerak naik dari bawah setpoint ke atas, kemudian kembali di bawah setpoint, dan seterusnya. Dalam kasus terjadi perubahan yang cukup cepat, sebuah diferensial on-off atau histeresis ditambahkan untuk operasi kontroler untuk mencegah kerusakan kontaktor dan katup. Kontroler tipe on/off biasanya digunakan pada pengendalian yang tidak memerlukan angka tepat atau pada sistem alarm. Kontroler ini menggunakan relay menempel, yang harus secara manual direset, dan digunakan untuk menutup proses ketika suhu tertentu tercapai.

\subsection{Kontroler Proporsional}

Kontroler proporsional dirancang untuk menghilangkan efek terkait dengan kondisi on-off. Sebuah kontroler proporsional mengurangi energi rata-rata yang harus dipasok ke pemanas karena suhu mendekati setpoint. Hal ini memiliki efek memperlambat pemanas sehingga tidak akan terjadi lonjakan suhu, namun akan mendekati setpoint dan mempertahankan suhu yang stabil. Tindakan proporsi dapat dicapai dengan memutar output dan off untuk interval waktu yang singkat. Tindakan proporsi terjadi dalam sebuah "band proporsional" di sekitar suhu setpoint. Di luar band ini, fungsi kontroler sebagai unit on-off, dengan output baik penuh pada on (di bawah band) atau sepenuhnya off (di atas band). Namun, dalam band, output adalah dihidupkan dan dimatikan dalam rasio perbedaan pengukuran dari setpoint. Pada setpoint (titik tengah dari band proporsional), output rasio on dan off adalah 1:1, yaitu waktu on dan off terjadi dalam waktu yang sama. Jika suhu lebih dari setpoint, on-dan off-kali bervariasi dalam proporsi dengan perbedaan suhu. Jika suhu berada di bawah setpoint, output akan lebih lama, jika suhu terlalu tinggi, output akan dimatikan lagi.

\subsection{Kontroler PID (Proporsional Integral Derivatif)}

Kontroler ini menggabungkan kontrol proporsional dengan dua penyesuaian tambahan, yang membantu unit otomatis mengkompensasi perubahan dalam sistem. Penggunaan tipe proporsional saja biasanya menghasilkan lonjakan (overshoot) pada respon outputnya serta selalu terjadi selisih antara output dan nilai setpointnya (steady state error). Untuk menghilangkan efek overshoot digunakan parameter derivatif, sementara untuk memperoleh nilai sekecil mungkin steady state errornya diperlukan parameter integral dalam kontrolernya.

\subsection{Thyristor atau Silicon Controlled Rectifier (SCR)}

Thyristor dirancang untuk mengendalikan daya AC hingga $10 \mathrm{MW}$ dengan rating arus sebesar $2 \mathrm{kA}$ pada tegangan $1800 \mathrm{~V}$ dan frekuensi kerjanya dapat mencapai $50 \mathrm{kHz}$. Tahanan konduktif dinamis suatu thyristor sekitar 0,01 sampai $0,1 \quad \Omega$ sedangkan tahanan reversenya sekitar $100 \mathrm{k} \Omega$ atau lebih besar lagi. 

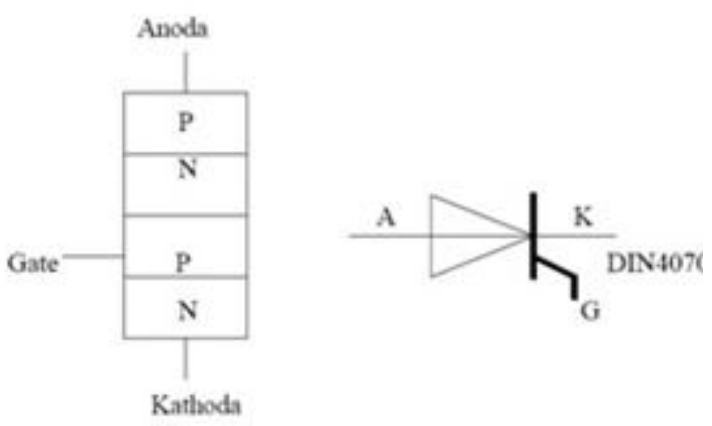

Gambar 2. Konstruksi dasar thyristor dan simbolnya

SCR mempunyai tiga buah elektroda, yaitu Anoda, Kathoda dan Gate dimana anoda berpolaritas positif dan kathoda berpolaritas negatip sebagai layaknya sebuah dioda penyearah (rectifier). Kaki Gate juga berpolaritas positip. Gambar 2 memperlihatkan SCR dengan simbolnya.

\subsection{Penyulutan SCR}

SCR dapat dihidupkan dengan arus penyulut singkat melalui terminal Gate, dimana arus gate ini akan mengalir melalui junction antara gate dan kathoda dan keluar dari kathodanya. Arus gate ini harus positip besarnya sekitar 0,1 sampai $35 \mathrm{~mA}$ sedangkan tegangan antara gate dan kathodanya biasanya 0,7 volt. Jika arus anoda ke kathoda turun dibawah nilai minimum (Holding Current $=\mathrm{I}_{\mathrm{HO}}$ ), maka SCR akan segera mati (off). Untuk SCR yang berkemampuan daya sedang, besar $\mathrm{I}_{\mathrm{HO}}$ sekitar $10 \mathrm{~mA}$. Tegangan maksimum arah maju akan terjadi jika gate dalam keadaan terbuka atau $\mathrm{I}_{\mathrm{GO}}=0$. Jika arus gate diperbesar dari $\mathrm{I}_{\mathrm{GO}}$, misal $\mathrm{I}_{\mathrm{Gl}}$, maka tegangan majunya akan lebih rendah lagi. Gambar 3 memperlihatkan salah satu cara penyulutan SCR dengan sumber searah (dc), dimana SCR akan bekerja dengan indikasi menyalanya lampu dengan syarat saklar PB1 dan PB2 di ON kan terlebih dahulu.

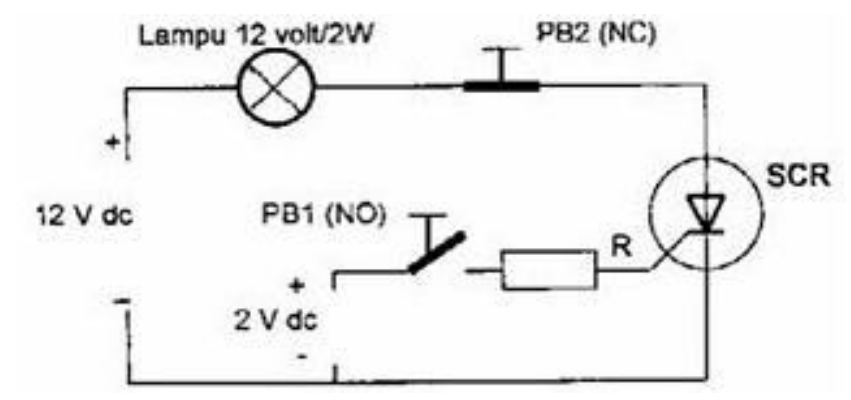

Gambar 3. Penyulutan SCR Dengan Sumber DC

Triggering untuk penyulutan SCR dengan sumber DC ini tidak perlu dilakukan secara terus menerus, jika saklar PB1 dibuka, maka lampu akan tetap menyala atau dengan perkataan lain SCR tetap bekerja. Gambar 4 memperlihatkan cara penyulutan SCR dengan sumber bolakbalik (AC).

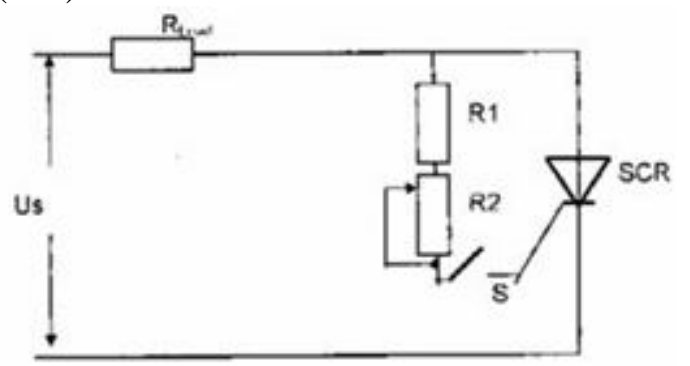

Gambar 4. Penyulutan SCR Dengan Sumber AC

Dengan mengatur nilai R2 (potensiometer), maka kita seolah mengatur sudut penyalaan SCR. Untuk penyulutan SCR dengan sumber arus bolak-balik, harus dilakukan secara terus menerus, jadi saklar $\mathrm{S}$ jika dilepas, maka SCR akan kembali tidak bekerja.

Gambar 5 memperlihatkan bentuk tegangan dan pada terminal SCR dan beban. Pengendalian sumber daya dengan SCR terbatas hanya dari $0^{\circ}$ sampai $90^{\circ}$.
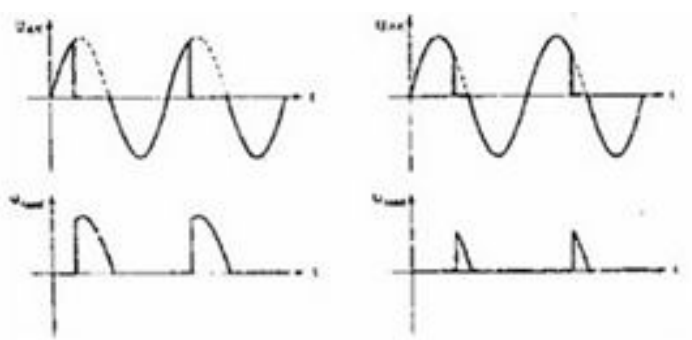

Gambar 5. Bentuk Tegangan Pada Terminal SCR Dan Beban 


\subsection{Instrumentasi pengendalian suhu}

Instrumentasi pengendalian suhu dalam mesin sintering furnace ini diperlihatkan pada gambar 6 dan 7. Gambar 6 adalah rangkaian automatic temperatur controllernya, sedangkan gambar 7 memberikan ilustrasi tentang rangkaian pemanas pada mesin ini.

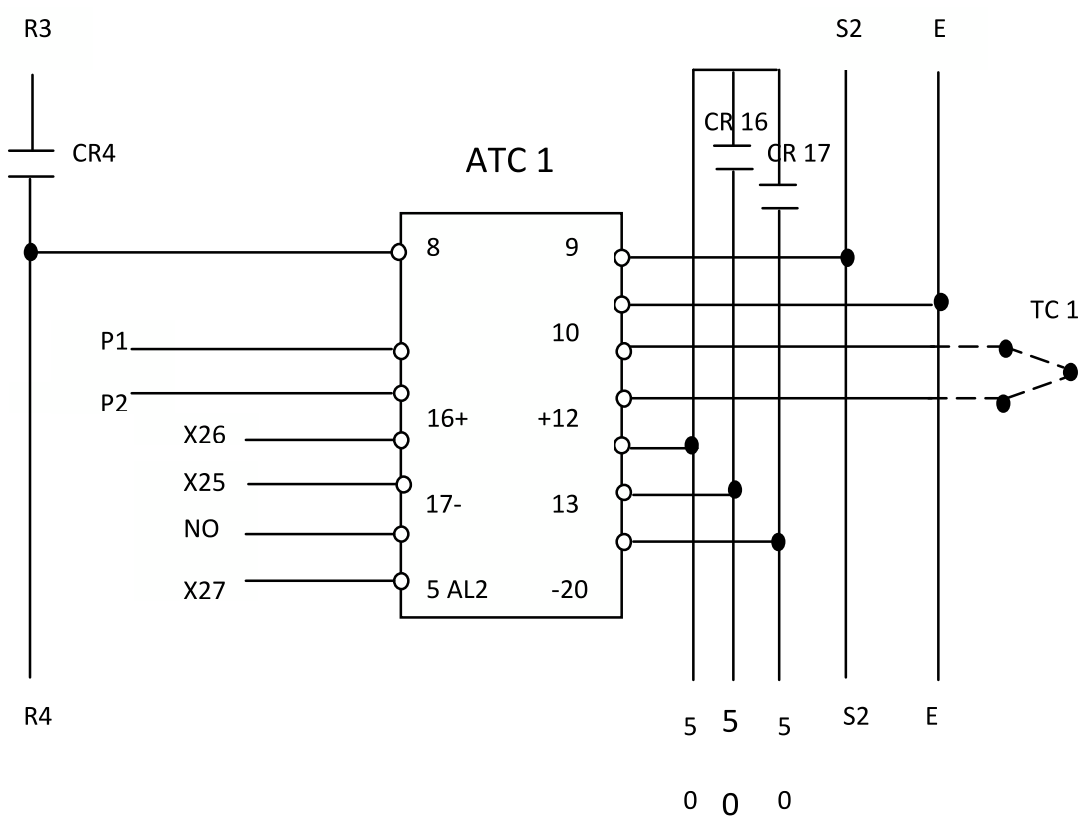

Gambar 6. Rangkaian Automatic Temperatur Controller

Simbol pada gambar 6 adalah sebagai berikut:

CR $4=$ Suhu control source 100V

$\mathrm{P} 1$ dan $\mathrm{P} 2=\mathrm{DC} 20 \mathrm{~mA}$

X25 = Input Alarm Over heat

X26 = Input alarm Temperatur

TC1 $=$ Thermocouple

CR16 = Pattern 1

CR $17=$ Pattern 2

$\mathrm{E} \quad=$ Ground

Untuk pengukuran suhu furnace dimulai dari tranduser berupa thermocouple tipe $-\mathrm{R}$ yang berfungsi sebagai sensor suhu dan tegangan keluaran yang dihasilkan dari transduser kemudian masuk ke digital indicating controller sebagai tampilan besaran nilai suhu, Automatic Temperatur Controler menjaga nilai Set Point. Apabila terdapat perbedaan, berarti suhu yang terjadi belum sama dengan suhu yang diinginkan. Automatic Temperatur Controler sebagai yang mengontrol elemen pemanas secara otomatis akan melakukan aksi pengendalian suhu yaitu memberikan output ke SCR (Silicon controlled Rectifier) sehingga tercapai suatu keadaan dimana nilai set point akan sama atau mendekati dengan nilai tegangan umpan balik keluaran sensor suhu. Dalam pengendalian suhu mesin sintering furnace yang merupakan pengendali suhu pada elemen pemanas adalah Automatic Temperature Controller. 


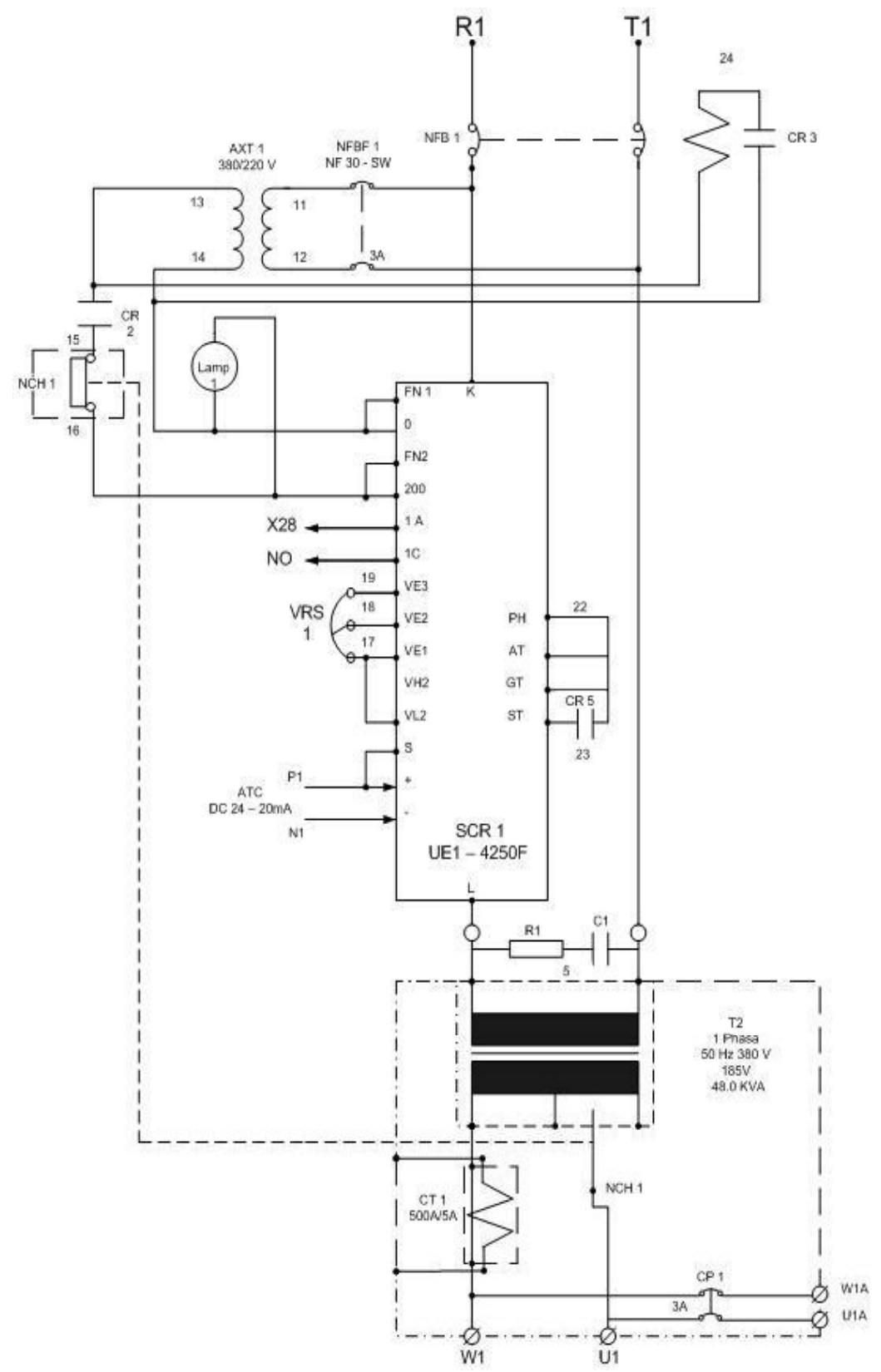

Gambar 7. Rangkaian Untuk Heater Mesin Sintering Furnace

Notasi pada gambar 7 adalah sebagai berikut:
AXT1 $=$ Trafo Step Down 380V/220V
CR $2=$ Sumber SCR
NCH $5=$ Saklar
X28 = Thyristor Alarm
$107,108,109=$ Potensio Meter
P4, N4 = Input dari ATC DC 4-20mA
CR 5
= Heater Operation
T4
= Trafo Step Down 380/185
CT $\quad=$ Trafo Arus 500/5A
CR $3=$ NFB Trip

Mekanisme proses pengendalian suhunya berlangsung sebagai berikut:

1. Main brake (NFB1) on secara manual maka arus listrik akan mengalir menuju SCR dan NFBF1

2. Setelah NFBF1 on maka arus listrik akan mengalir menuju transformator step down $(380 \mathrm{~V} / 220 \mathrm{~V})$ yang memberikan tegangan input SCR (Silicon Controlled Rectifier) sebesar 220V.

3. SCR bekerja setelah mendapatkan sinyal dari ATC (Automatic Temperature Controller) berupa tegangan sebesar 4- 
20mA DC. ATC akan memberikan masukan sampai pembacaan thermocouple sesuai dengan suhu setpoint masing-masing zone pada ATC.

4. Output arus dan tegangan dari SCR kemudian masuk ke transformator step down (380V/185) lalu masuk ke Trafo arus setelah itu masuk ke heater.

\section{Hasil pengukuran dan analisis}

Pengambilan data dilakukan dengan tujuan untuk mengetahui kondisi arus dan tegangan mesin sintering furnace pada saat beroperasi. Pengukuran dilakukan pada masing-masing zone menggunakan ampermeter dan voltmeter. Diagram pengukurannya diperlihatkan pada gambar 8 .

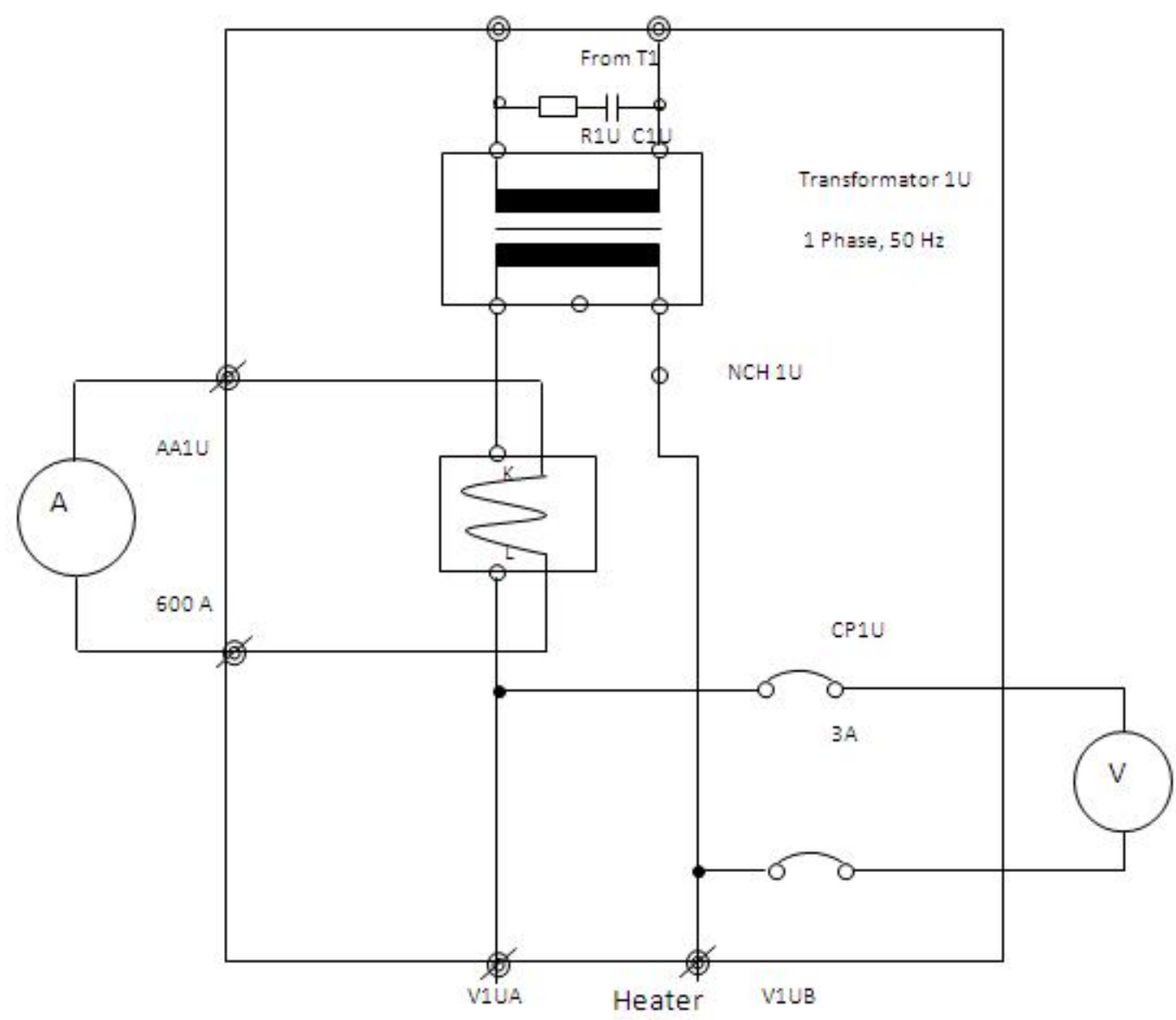

Gambar 8. Rangkaian pengukuran arus dan dan tegangan pada masing - masing zone

Hasil pengukuran arus dan tegangan pada masing-masing zone mesin sintering furnace diperlihatkan pada tabel 1 dan grafiknya diberikan pada gambar 9 . 
Tabel 1. Data Arus dan Tegangan Mesin Sintering Furnace

\begin{tabular}{|c|c|c|c|c|c|c|c|c|c|c|c|c|c|c|c|}
\hline \multirow[t]{2}{*}{ No } & \multirow[t]{2}{*}{ Jam } & \multicolumn{2}{|c|}{ Zone 1 U } & \multicolumn{2}{|c|}{ Zone 1 B } & \multicolumn{2}{|c|}{ Zone 2} & \multicolumn{2}{|c|}{ Zone 3} & \multicolumn{2}{|c|}{ Zone 4} & \multicolumn{2}{|c|}{ Zone 5} & \multicolumn{2}{|c|}{ Zone 6} \\
\hline & & (A & ) & & v) & & $(\mathbf{V})$ & (1) & (v) & (1) & & (1) & & (A) & \\
\hline 1 & $7: 00$ & 21 & 5 & 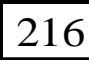 & 185 & & 185 & $\pi$ & 185 & & & 216 & & 216 & \\
\hline & & & & & of & & 5 & & 103 & & & & & & \\
\hline & 9 & 21 & 185 & 214 & 185 & & 5 & 214 & $\mathrm{~J}$ & 214 & 185 & 215 & 185 & 5 & 105 \\
\hline & $: 00$ & & 185 & 216 & 185 & & 5 & 210 & 5 & 215 & 185 & 2 & 185 & 6 & 105 \\
\hline & $1: 00$ & 210 & 1 & 21 & 185 & 210 & 35 & 21 & 85 & 2 & 185 & 214 & 185 & 15 & 185 \\
\hline & $13: 00$ & 210 & כ5 & 214 & 185 & 210 & 185 & 216 & 185 & 216 & 85 & 21 & 18 & 6 & 185 \\
\hline & $14: 00$ & 200 & 185 & 207 & 185 & 210 & 185 & 215 & 185 & 216 & 85 & 215 & 18 & 216 & 185 \\
\hline & $15: 00$ & 200 & 185 & 203 & 185 & 215 & 185 & 216 & 185 & 214 & 85 & 216 & 18 & 215 & 8. \\
\hline & $16: 00$ & 198 & 185 & 206 & 185 & 216 & 185 & 216 & 185 & 216 & 185 & 216 & 185 & 216 & 185 \\
\hline & $17: 00$ & 203 & 185 & 208 & 185 & 16 & 185 & 214 & 185 & 214 & 185 & 215 & 185 & 216 & 185 \\
\hline & $18: 00$ & 207 & 185 & 211 & 185 & 215 & 185 & 216 & 185 & 216 & 185 & 216 & 185 & 216 & 185 \\
\hline & $19: 00$ & 210 & 185 & 216 & 185 & 216 & 185 & 216 & 185 & 216 & 185 & 215 & 185 & 216 & 185 \\
\hline & $20: 00$ & 213 & 185 & 216 & 185 & 214 & 185 & 215 & 185 & 216 & 185 & 214 & 185 & 216 & 185 \\
\hline & $21: 00$ & 216 & 185 & 216 & 185 & 216 & 185 & 216 & 185 & 216 & 185 & 216 & 185 & 216 & 185 \\
\hline & $22: 00$ & 216 & 185 & 215 & 185 & 21 & 185 & 215 & 185 & 215 & 185 & 214 & 185 & 15 & 185 \\
\hline & $23: 00$ & 21 & 185 & 214 & 185 & 21 & 185 & 216 & 185 & 215 & 185 & 216 & 85 & 16 & 185 \\
\hline & $0: 00$ & 21 & 185 & 216 & 185 & 21 & 185 & 216 & 185 & 216 & 185 & 216 & 85 & 16 & 85 \\
\hline & $1: 00$ & 21 & 185 & 216 & 185 & 21 & 185 & 214 & 185 & 216 & 185 & 216 & 185 & 14 & 85 \\
\hline & $2: 00$ & 216 & 185 & 216 & 185 & 216 & 185 & 216 & 185 & 216 & 185 & 214 & 185 & 215 & 185 \\
\hline
\end{tabular}

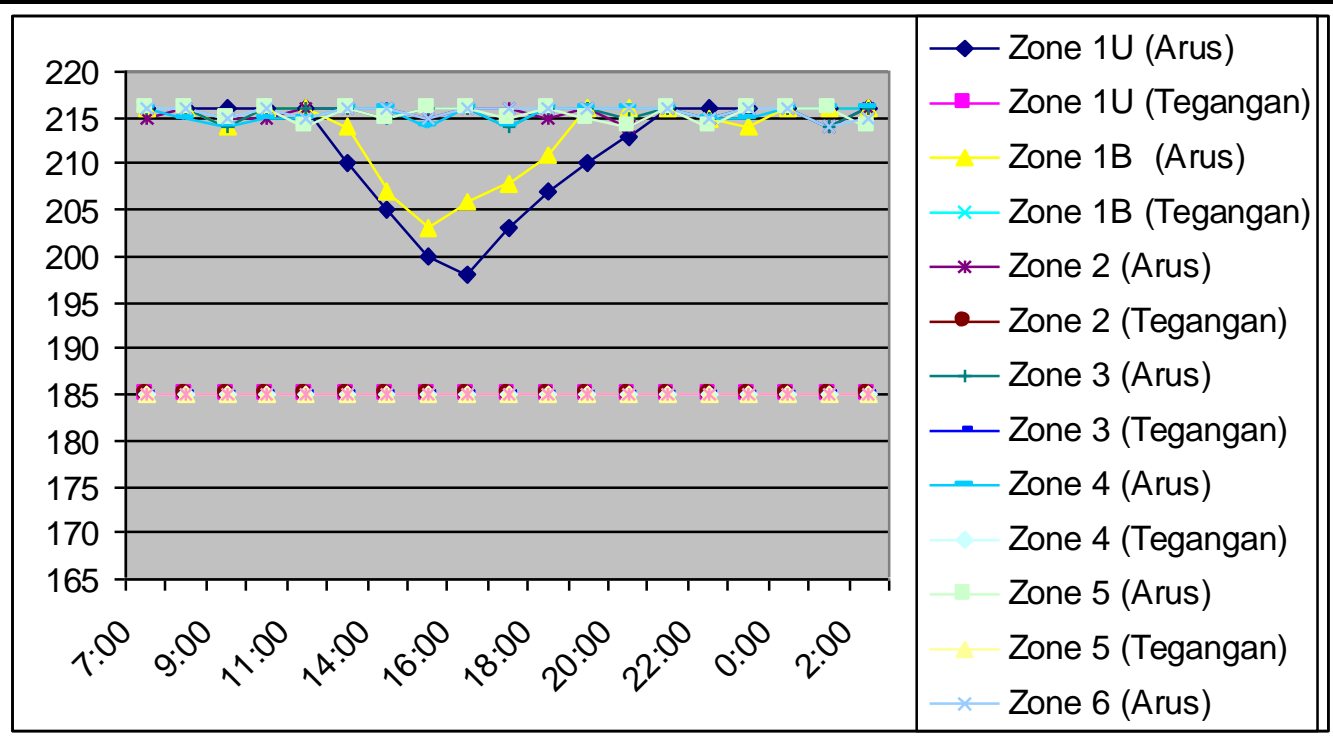

Gambar 9. Arus dan tegangan Zone 1U sampai dengan zone 6 mesin sintering furnace

Dari tabel dan grafik terlihat terjadi penurunan arus heater pada area zone $1 \mathrm{U}$ dan 1B pada pukul 13: 00 sampai dengan pukul 20:00, dan untuk zone $1 \mathrm{U}$ penurunan arus dari 216 A menjadi 210 A sedangkan untuk Zone 1B dari 216 A menjadi 209 A untuk tegangan masih tetap stabil. Proses pengendalian untuk menaikan arus pada 
heater zone 1U-1B adalah dengan menambah output arus pada SCR dari $90 \%$ menjadi $95 \%$ untuk setting output pada SCR maksimal $100 \%$.

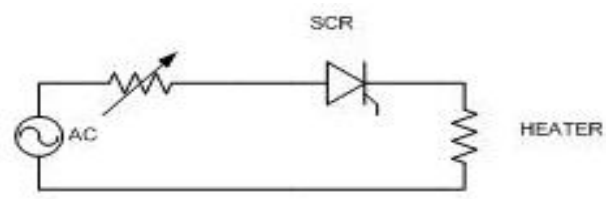

Gambar 10 memperlihatkan rangkaian skematik pengaturan output pada SCR. Untuk menaikan suhu heater dapat dilakukan dengan cara menaikan arus pada SCR sehingga heater lebih cepat panas. Data suhu yang diperoleh dari instrumen pengukur suhu yang terdapat pada panel mesin diperlihatkan pada tabel 2 .

Gambar 10. Pengaturan output SCR

Tabel 2. Data suhu mesin sintering furnace

\begin{tabular}{|c|c|c|c|c|c|c|c|c|}
\hline \multirow[t]{2}{*}{ No. } & \multirow[t]{2}{*}{ Jam } & \multicolumn{7}{|c|}{ SUHU ZONA UTAMA $\left({ }^{\circ} \mathrm{C}\right)$} \\
\hline & & $1 \mathrm{U}$ & $1 \mathrm{~B}$ & 2 & 3 & 4 & 5 & $\overline{6}$ \\
\hline 1 & $7: 00$ & 1155 & 1050 & 1155 & 1155 & 1155 & 1150 & 1140 \\
\hline & $8: 00$ & 1155 & 1050 & 1155 & 1155 & 1155 & 1150 & 1140 \\
\hline & $9: 00$ & 1155 & 1050 & 1155 & 1155 & 1155 & 1150 & 1140 \\
\hline & $10: 00$ & 1155 & 1050 & 1155 & 1155 & 1155 & 1150 & 1140 \\
\hline & $11: 00$ & 1155 & 1050 & 1155 & 1155 & 1155 & 1150 & 1140 \\
\hline & $13: 00$ & 1150 & 1047 & 1155 & 1155 & 1155 & 1150 & 1140 \\
\hline & $14: 00$ & 1142 & 1042 & 1155 & 1155 & 1155 & 1150 & 1140 \\
\hline & $15: 00$ & 1138 & 1038 & 1155 & 1155 & 1155 & 1150 & 1140 \\
\hline & $16: 00$ & 1140 & 1040 & 1155 & 1155 & 1155 & 1150 & 1140 \\
\hline & $17: 00$ & 1143 & 1043 & 1155 & 1155 & 1155 & 1150 & 1140 \\
\hline & $18: 00$ & 1146 & 1046 & 1155 & 1155 & 1155 & 1150 & 1140 \\
\hline & $19: 00$ & 1150 & 1050 & 1155 & 1155 & 1155 & 1150 & 1140 \\
\hline & $20: 00$ & 1152 & 1050 & 1155 & 1155 & 1155 & 1150 & 1140 \\
\hline & $21: 00$ & 1155 & 1050 & 1155 & 1155 & 1155 & 1150 & 1140 \\
\hline & $22: 00$ & 1155 & 1050 & 1155 & 1155 & 1155 & 1150 & 1140 \\
\hline & $23: 00$ & 1155 & 1050 & 1155 & 1155 & 1155 & 1150 & 1140 \\
\hline & $0: 00$ & 1155 & 1050 & 1155 & 1155 & 1155 & 1150 & 1140 \\
\hline & $1: 00$ & 1155 & 1050 & 1155 & 1155 & 1155 & 1150 & 1140 \\
\hline & $2: 00$ & 1155 & 1050 & 1155 & 1155 & 1155 & 1150 & 1140 \\
\hline
\end{tabular}

Dari tabel 2 terlihat penurunan suhu pada zone 1U dan 1B antara pukul 13:00 sampai 20:00. untuk untuk zone 1 penurunan suhu terjadi pada pukul 13:00 dari $1155^{\circ} \mathrm{C}$ menjadi $1150^{\circ} \mathrm{C}$ dan pada zone $1 \mathrm{~B}$ dari $1050^{\circ} \mathrm{C}$ menjadi $1047^{\circ} \mathrm{C}$. Grafik perubahan suhu pada mesin sintering furnace diberikan pada gambar 11. Karena respon perubahan suhu sangat lambat, maka diperlukan kurang lebih 7 jam untuk mengembalikan suhu mesin ke suhu setpointnya. 


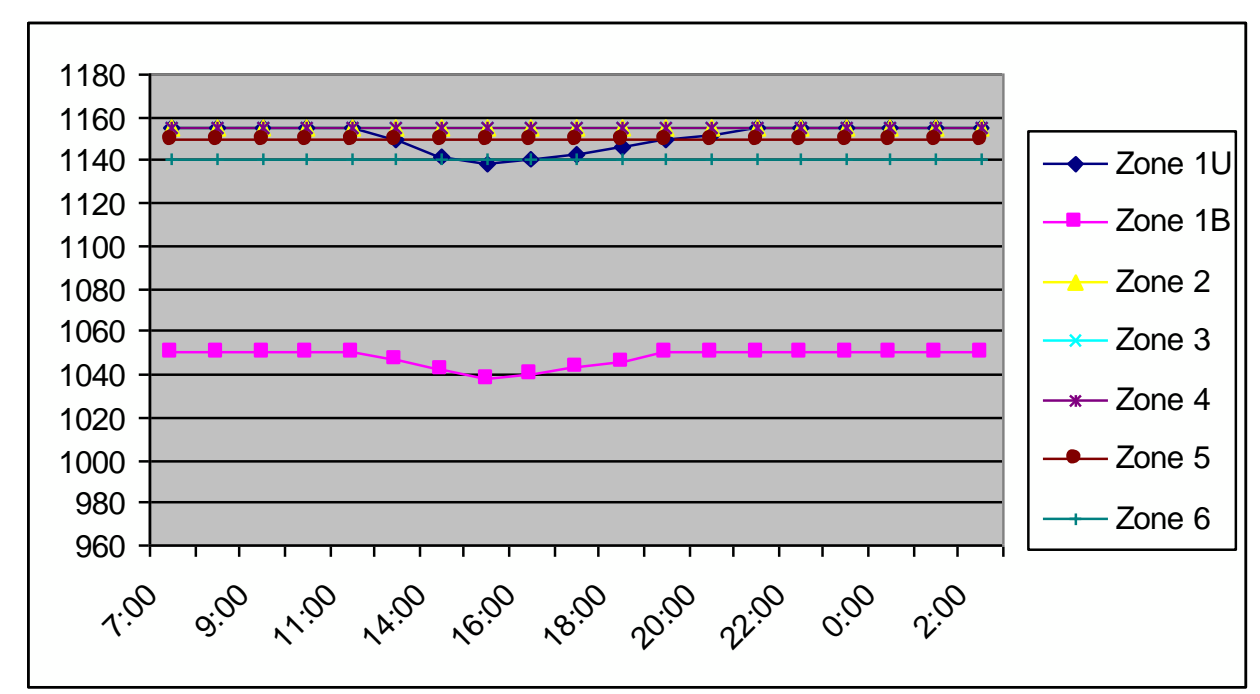

Gambar 11. Penurunan Suhu Zone 1U sampai dengan zone 6 mesin

Tabel 3 memperlihatkan nilai error (selisih) suhu aktual dengan suhu setpointnya. Nilai error tersebut dihitung dari selisih antara suhu setpoint $\left(1155^{\circ} \mathrm{C}\right)$ dengan suhu sebenarnya yang dihitung dengan instrumen suhu. Dari tabel terlihat bahwa nilai error tertinggi sebesar 17 poin yakni pada penurunan suhu $1138^{\circ} \mathrm{C}$.

Tabel 3. Nilai error pada penurunan suhu Zone $1 \mathrm{U}$

\begin{tabular}{|c|c|c|}
\hline \multicolumn{3}{|c|}{ ZONE 1U } \\
\hline $\begin{array}{c}\text { suhu setpoint } \\
\left({ }^{\circ} \mathbf{C}\right)\end{array}$ & $\begin{array}{c}\text { suhu } \\
\text { aktual } \\
\left({ }^{\circ} \mathbf{C}\right)\end{array}$ & $\begin{array}{c}\text { Nilai } \\
\text { eror }\end{array}$ \\
\hline 1155 & 1050 & 5 \\
\hline 1155 & 1142 & 13 \\
\hline 1155 & 1138 & 17 \\
\hline 1155 & 1140 & 15 \\
\hline 1155 & 1143 & 12 \\
\hline 1155 & 1146 & 9 \\
\hline 1155 & 1150 & 5 \\
\hline 1155 & 1152 & 3 \\
\hline
\end{tabular}

Sementara itu, tabel 4 menggambarkan nilai error pada zone 1B dan grafiknya perubahan errornya diperlihatkan pada gambar 12 .
Tabel 4. Nilai error pada penurunan suhu Zone 1B

\begin{tabular}{|c|c|c|}
\hline \multicolumn{3}{|c|}{ ZONE 1B } \\
\hline $\begin{array}{c}\text { Suhu } \\
\text { setpoint } \\
\left({ }^{\circ} \mathbf{C}\right)\end{array}$ & $\begin{array}{c}\text { Suhu } \\
\text { aktual } \\
\left({ }^{\circ} \mathbf{C}\right)\end{array}$ & $\begin{array}{c}\text { Nilai } \\
\text { error }\end{array}$ \\
\hline 1050 & 1047 & 3 \\
\hline 1050 & 1042 & 8 \\
\hline 1050 & 1038 & 12 \\
\hline 1050 & 1040 & 10 \\
\hline 1050 & 1043 & 7 \\
\hline 1050 & 1046 & 4 \\
\hline
\end{tabular}

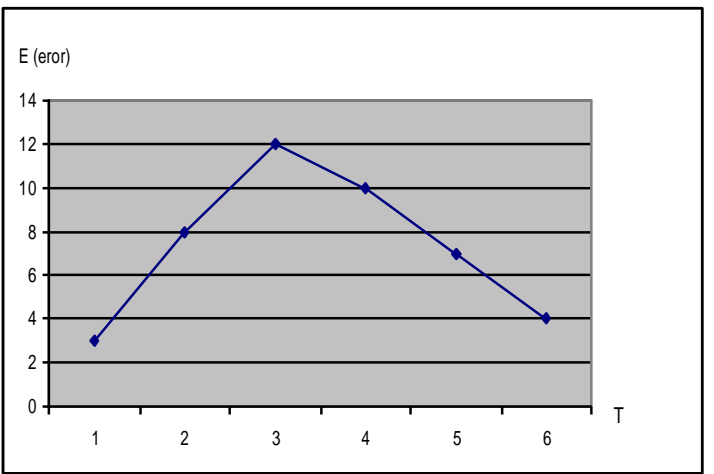

Gambar 12. Grafik perubahan nilai error suhu pada Zone $1 \mathrm{U}$

\section{Kesimpulan}

Makalh ini telah menguraikan tentang pengendalian suhu secara elektronis pada mesin sintering furnace menggunakan komponen semikonduktor thyristor (SCR). Faktor suhu yang konstan menjaga agar 
produk yang dihasilkan dari proses sintering berkualitas baik. Hasil pengamatan memperlihatkan bahwa pengendali thyristor yang digunakan berhasil menaikkan kembali suhu yang turun dalam mesin sintering furnace, meskipun terlihat bahwa responnya berorde jam (sangat lambat). Penelitian berikutnya yang dapat dilakukan untuk meningkatkan kecepatan respon adalah dengan menerapkan tipe pengendali PID dalam kasus tersebut. Aplikasi PLC dalam proses pengendalian suhu seperti yang telah dilakukan oleh Fattah (2011) juga menarik untuk diterapkan agar diperoleh hasil yang lebih baik.

\section{Daftar Pustaka}

Fattah, A. (2011), Rancang Bangun Sistem Kendali Suhu Furnace Kalsinasi Zirkonium Dengan Menggunakan PLCT100md1616+, Skripsi pada Prodi Elektronika dan Instrumentasi FMIPA UGM.

Herhady, R. D. dan Sukarsono, R. (2007), Pengaruh Suhu dan Waktu Sintering terhadap Kualitas Bahan Bakar Kernel $\mathrm{UO}_{2}$ dalam Furnace jenis Fluidized Bed, Prosiding Seminar Nasional ke-13 Teknologi dan Keselamatan PLTN serta Fasilitas Nuklir, Jakarta, 6 Nopember 2007, hlm. 67-74.

Kang, S. J. L. (2005), Sintering: Densification, Grain Growth \& Microstructure, Elsevier ButterworthHeinemann, hlm. 3.

Subiyanto, H. dan Subowo (2003), Pengaruh Temperatur Sintering terhadap Sifat Mekanik Keramik Insulator Listrik, Jurnal Teknik Mesin, Volume 3, Nomor 18, Januari 2003, hlm 16-19.

Sutarya, D. (2008), Analisis Unjuk Kerja Thermocouple W3Re25 Pada Suhu Penyinteran $1500^{\circ} \mathrm{C}$, Majalah Ilmiah Pengelolaan Instalasi Nuklir (PIN) Vol. 1, No. 1, April 2008, hlm. 17-26.

Wikipedia (2011), diambil dari http://en.wikipedia.org/wiki/Sintering, tanggal 7 Agustus 2011 pukul 10.23. 